\title{
Canada's National Emergency Stockpile System: time for a new long-term strategy
}

\author{
Scott Laing MD, Ellen Westervelt BHSc
}

Cite as: CMAJ 2020 July 13;192:E810-1. doi: 10.1503/cmaj.200946; early-released June 25, 2020

$\mathbf{R}$ ecent media reports identified that millions of personal protective equipment (PPE) supplies in Canada's National Emergency Stockpile System (NESS) have expired and gone to waste. ${ }^{1}$ Government officials and health care organizations are also trying urgently to secure new stock to address widespread shortages. ${ }^{2}$ Management of emergency stockpiling has proven challenging for Canada and other countries, including the United States and Australia, particularly regarding stock expiration and financial waste. ${ }^{3,4}$ We propose an alternative long-term strategy to maintain Canada's stockpile that aims to minimize waste and ensure adequate supply, based on consideration of other countries' pandemic responses and stockpile audits.

The NESS was established in 1952 during the Cold War and consisted of a mobile hospital and the social supports needed for a nuclear disaster response. ${ }^{5}$ The NESS evolved following national and international disasters to more broadly include medical equipment, pharmaceuticals and social services supplies. ${ }^{5}$ After the severe acute respiratory syndrome (SARS) pandemic in 2003, the Public Health Agency of Canada (PHAC) was established and the NESS assets were transferred from Health Canada to PHAC. ${ }^{5}$ The SARS pandemic also led to both the Emergency Management $A c t^{6}$ and the Federal Emergency Response Plan, ${ }^{7}$ which outlines that the Government of Canada should lead the coordination of emergency responses to "all hazards." 6,7

As of the latest public NESS audit (2010), the estimated value of all assets was $\$ 300$ million, annual operations budgets were $\$ 4$ million and annual warehouse leases were $\$ 7.7$ million. ${ }^{5}$ Supplies were stored in 11 warehouses across the country and had been deployed 128 times in the previous 25 years. ${ }^{5}$ The problem of expired supplies was raised in the 2010 NESS audit, as some supplies were found to date back to the 1960 s. ${ }^{8}$ Current stockpile maintenance plans rely on either deployment or disposal of supplies, but many supplies expire before use because deployment occurs only once other stocks are depleted. ${ }^{8}$ Media reports indicate that Canada's stockpile still contains many expired supplies. ${ }^{1}$ Exact quantities of available supplies are also unknown, ${ }^{1}$ because the NESS lacks an electronic inventory management system and the latest publicly available data are from the 2010 audit. ${ }^{8}$ The Government of Canada is currently struggling to

\section{KEY POINTS}

- The coronavirus disease 2019 pandemic has put the spotlight on problems with the personal protective equipment supply chain in Canada and elsewhere.

- Canada's National Emergency Stockpile System (NESS) was last audited in 2010; a problem with expired supplies was noted then and persists to this day.

- Emergency supply stockpiles are expensive to maintain, and management of expired supplies generates substantial financial and material waste.

- A better approach may be to integrate the NESS with the commercial supply through a "prime vendor" that could minimize financial and material waste by selling supplies to health care organizations; this would continually refresh the stockpile, ensuring an adequate unexpired emergency supply, and provide much-needed supply and demand data for emergency responses.

coordinate timely procurement of new $\mathrm{PPE}^{2}$ owing to long wait times for order fulfillment, which was also identified in the 2010 audit. ${ }^{8}$ The resulting PPE shortages have hindered provision of some health services, particularly in the community, where many family doctors have had limited access to essential PPE. ${ }^{9}$ These supplies may be purchased through third-party medical supply companies, which becomes difficult when demand increases.

After the novel influenza A (H1N1) pandemic in 2009, an American analysis highlighted problems that arose with the PPE supply chain. ${ }^{10}$ Many organizations substantially increased orders to build their own stockpiles and, when orders were cancelled or partially filled, they placed orders with multiple vendors. When the government tried to help coordinate a response, considerable challenges arose; supply and demand could not be predicted because no centralized ordering system existed to provide supply and demand data, and private vendors resisted sharing their data for fear of competition. ${ }^{10}$ These challenges led to recommendations to monitor PPE usage and centralize ordering information. ${ }^{10}$

Like Canada, the US maintains its Strategic National Stockpile (SNS) to coordinate emergency responses. ${ }^{3}$ A review of the SNS also revealed high expenses owing to supplies expiring before they could be used. ${ }^{3}$ To reduce the impact of stock expiration, the US elected to 
extend expiration dates beyond manufacturer's posted dates. ${ }^{3}$ Although this approach may be effective in the short term, it has not solved the expiration problem. ${ }^{3}$

An audit of the Australian National Medical Stockpile (ANMS) revealed that Australia's stockpile strategies are wasteful and expensive. ${ }^{4}$ In the 10 years preceding that audit, Australians invested \$750 million into the ANMS. Of that, nearly \$250 million of stock expired, generating disposal costs of $\$ 75$ million. ${ }^{4}$ Australia's stockpile maintenance strategy involves stock rotation, returning expired stock and shelf-life extensions. ${ }^{4}$

It is past time for Canada to adopt a new, long-term stockpile strategy - one that utilizes supply and demand data, ${ }^{10}$ ensures supplies are used before they expire, ${ }^{3,4,8}$ and is financially responsible., ${ }^{3,4,8}$

One approach could be to mandate that all suppliers report orders to a central agency for tracking. ${ }^{10}$ Such a body could better coordinate stockpile dispensing and initiate earlier manufacturing responses. ${ }^{10}$ Another approach could be to further develop disposal ${ }^{8}$ and shelf-life extension programs. ${ }^{3,4}$ However, neither approach would solve problems with stock expiration or consequent financial and material waste. ${ }^{3,4}$

A better approach may be to integrate the NESS with the commercial supply. ${ }^{10}$ Integration could be accomplished through a "prime vendor" ${ }^{4}$ Crown corporation or not-for-profit organization. The prime vendor would manage inventory, procurement, contract negotiations, data reporting, logistics and distribution. ${ }^{4}$ This organization could be modelled after shared services organizations (SSOs), which procure supplies through joint purchasing agreements to save money and ensure stable and fair pricing. ${ }^{11}$ The prime vendor would keep stockpile warehouses full and sell supplies to hospitals, private clinics and long-term care facilities for routine use, thereby keeping stocks fresh and ensuring adequate supply for emergency responses. The Government of Canada could use the supply and demand data from sales to better coordinate emergency responses and anticipate shortages to trigger earlier manufacturing responses. ${ }^{10}$ The types of supplies stocked could be reviewed regularly to ensure relevance. If this approach is effective, then the prime vendor could expand operations to include critical care products and pharmaceuticals.

We recognize that the proposed prime-vendor approach will not solve current shortages ${ }^{1}$ or international procurement issues. ${ }^{2}$ It would have challenges, including manufacturer selection, optimizing the stockpile size, inventory management logistics and bureaucratic obstacles. Therefore, the prime vendor could start on a small scale and expand only when prepared.

Stock expiration is an important challenge with national stockpiles. Accordingly, a new long-term PPE supply-chain solution is urgently needed. Selling and refreshing supplies to maintain a minimum stock for emergencies could ensure adequate supply and minimize wasted resources. Canada needs to act now to be better prepared for the next emergency.

\section{References}

1. Leo G. Health minister reviewing management of Canada's emergency stockpile. CBC News 2020 Apr. 15, updated 2020 Apr. 16. Available: www.cbc.ca/news/ canada/saskatchewan/heath-minister-emergency-stockpile-1.5530081 (accessed 2020 Apr. 16).

2. Cochrane D, Harris K. Canada building its own PPE network in China. CBC News 2020 Apr. 13, updated 2020 Apr. 16. Available: www.cbc.ca/news/politics/canada -building-own-ppe-supply-chain-in-china-1.5530259 (accessed 2020 Apr. 16).

3. The strategic national stockpile: origin, policy foundations, and federal context. In: The Nation's Medical Countermeasure Stockpile: opportunities to improve the efficiency, effectiveness, and sustainability of the CDC Strategic National Stockpile: workshop summary. Washington (DC): National Academies Press; 2016. Available: www.ncbi.nlm.nih.gov/books/NBK396378 (accessed 2020 Apr. 19).

4. Management of the National Medical Stockpile. Auditor - general report No 53 of 2013-14. Canberra (AU): Department of Health, Australian National Audit Office; 2014.

5. Section 2: Evaluation of the National Emergency Stockpile System (NESS) Background. Ottawa: Public Health Agency of Canada; modified 2012 Aug. 28. Available: www.canada.ca/en/public-health/corporate/mandate/about-agency /office-evaluation/evaluation-reports/evaluation-national-emergency-stockpile -system/background-context.html\#background-3 (accessed 2020 Apr. 16).

6. Emergency Management Act (S.C. 2007, c. 15). Available: https://laws-lois justice.gc.ca/eng/acts/e-4.56/page-1.html (accessed 2020 Apr. 17).

7. Federal Emergency Response Plan, January 2011. Ottawa: Public Safety Canada; modified 2018 Jan. 31. Available: www.publicsafety.gc.ca/cnt/rsrcs/pblctns/ mrgnc-rspns-pln/index-en.aspx (accessed 2020 Apr. 17).

8. Section 3: Evaluation of the National Emergency Stockpile System (NESS) Findings. Ottawa: Public Health Agency of Canada; modified 2012 Aug. 28. Available: www.canada.ca/en/public-health/corporate/mandate/about-agency /office-evaluation/evaluation-reports/evaluation-national-emergency-stockpile -system/findings.html\#findings-1 (accessed 2020 Apr. 16).

9. Kupfer M. Mask shortage threatening family practices, doctors say. CBC News 2020 Mar. 31. Available: www.cbc.ca/news/canada/ottawa/mask-shortage -threatening-family-practices-1.5511360 (accessed 2020 Apr. 17).

10. Patel A, D'Alessandro MM, Ireland KJ, et al. Personal protective equipment supply chain: lessons learned from recent public health emergency responses. Health Secur 2017;15:244-52.

11. Shared services in health care: environmental scan. Ottawa: Canadian Agency for Drugs and Technologies in Health; 2011. Available: www.cadth.ca/media/ pdf/Health_SS_es_24_e.pdf (accessed 2020 Apr. 17).

\section{Competing interests: None declared.}

This article has been peer reviewed.

Affiliations: Department of Family Medicine (Laing), University of Ottawa; Procurement (Westervelt), Queensway Carleton Hospital, Ottawa, Ont.

Contributors: Scott Laing was responsible for the concept, background research and writing of the article. Ellen Westervelt was responsible for reviewing the article, providing constructive feedback and editing. Both authors approved the final version to be published and agreed to be accountable for all aspects of the work.

Disclaimer: The opinions expressed in this commentary are those of the authors and do not necessarily represent the views of the Queensway Carleton Hospital.

Correspondence to: Scott Laing, slain027@uottawa.ca 